The expansion engine is placed in the middle of the evacuated cylindrical copper casing, the dimensions of which are $75 \mathrm{~cm}$. long and $25 \mathrm{~cm}$. diameter. The casing also contains heat-exchanging spirals and a container of liquid air for the preliminary cooling of the helium. Helium is compressed to 25-30 atmospheres and is first cooled to the temperature of liquid air and then cooled by the expansion engine and regenerating spiral to about $8^{\circ} \mathrm{K}$.; the final liquefaction is produced by making use of the Joule-Thomson effect. This combination proves to be the most efficient method of liquefaction. The liquid helium is drawn off from the bottom of the liquefier by means of a tap.

Following the preliminary cooling to the temperature of liquid nitrogen, the liquefier starts after 45 minutes to liquefy helium at a rate of 1 litre per hour, consuming about 3 litres of liquid air per litre of liquid helium. This output we hope will shortly be increased, but even now it compares very favourably with the original method of making liquid helium, in which, according to Meissner (loc. cit.), the consumption is 6 litres of liquid air plus 5 litres of liquid hydrogen per litre of liquid helium. It is also evidently a considerable advantage to be able to dispense with liquid hydrogen as a preliminary cooling agent. Theoretically it would be possible in our case also to dispense with liquid air, but the size of the liquefier would then be impracticably large. Using liquid hydrogen as a cooling agent, the output of the liquefier could be increased about six times.

The same liquefier has also been used for liquefying hydrogen, which was passed through a special circuit under a pressure of a few atmospheres.

A detailed description of the apparatus will shortly be published elsewhere.

1 "Handbuch der Physik." Geiger and Scheel, vol. 11, p. 328. 'Z. Phys., 81, 816; 1933 .

\title{
Science and the Royal Academy
}

$\mathrm{I}^{\mathrm{F}}$ the art of the painter were to begin and end in mere representation, the coloured photograph would completely satisfy most people. Indeed, science, by the invention of the stereoscope, has furnished a means of actual representation in three dimensions which far surpasses in this respect even the greatest paintings that exist. It is a commonplace to hear, in any gallery, expressions of approval or otherwise based mainly upon such considerations.

Sir Joshua Reynolds, in his sixth discourse before the Royal Academy, says: "When the arts were in their infancy, the power of merely drawing the likeness of any object was considered one of its greatest efforts. The common people, ignorant of the principles of art, talk the same language even to this day." On the other hand Carlyle, quoting Goethe, points out that "In every object there is inexhaustible meaning; the eye sees in it what the eye brings means of seeing". The colour, arrangement, style or texture, design and rhythm can only fully appeal to those who have given the matter some thought, and who realise that "Art is Nature expressed through a personality".

Yet there must be rules underlying the making of a picture which give to it those fundamental qualities that ensure its survival through the ages. Although science has given the painter a wider range of reliable pigments, and the oils and mediums used by him are more refined and less liable to change, it is interesting to notice that this craft still employs identically the same kind of tools and methods that have been in use for centuries. The development of machinery, the vast accumulation of knowledge in all branches of human activity, the great advances in chemistry and physics, leave the artist undisturbed with his simple appliances. He still works in surroundings very similar to those that could have been found in the studios of Michael Angelo or Titian. The artist is probably unique in this, and acquires therefrom a peculiar position in the scheme of things; often being regarded by the ignorant as a kind of magician, by the intelligentsia as a species of poet, and sometimes by men of science as an overrated member of society, who seems in fact to have contributed nothing to the accumulations of unsorted knowledge.

A possible remedy for this state of affairs lies with the artists themselves. The old masters have left us pictures of the alchemist in his laboratory. Present-day artists have missed a great opportunity in not attempting to represent something of the atmosphere in which modern scientific experiments are frequently conducted. Surely there is wide scope here for artistic adventure. It is not merely a question of depicting some distinguished individual before a background of scientific apparatus. The figures, some in action and others eagerly note-taking, should be subsidiary to the general plan. There is often great beauty of colour and composition to be foundespecially in a physics laboratory-where some important work is afoot and being carried through, in dim light stabbed only by beams reflected from the instruments.

The one hundred and sixty-sixth annual exhibition of the Royal Academy, which was opened to the public on May 7, includes the famous bust of Prof. Einstein (1593) by Mr. Jacob Epstein. This has been purchased for the nation under the terms of the Chantrey Bequest. There is also a good portrait of Sir Robert Mond (146), painted by Mr. F. O. Salisbury, and an excellent picture of Prof. John Walton (with a microscope at his elbow) (248) by Mr. W. O. Hutchison. An attempt 
to portray a situation of scientific interest may be seen in No. 167, entitled "The Wilson Observer, 1933", by Winifred M. Abram. The portrait of Sir Almroth Wright (26) by Mr. Gerald F. Kelly exhibits a quality which will please all who are satisfied with photographic accuracy. Other portraits likely to interest readers of NATURE are those of Major C. H. Douglas, consulting engineer and economist (3), by Mr. Augustus E. John, R.A.; Prof. H. M. Macdonald, professor of mathematics in the University of Aberdeen (254), by Mr. R. G. Eves; Sir George Buckston Browne (1096), a miniature by Mr. P. Buckman. Since the portraits exhibited at the Academy are often of especial interest, a small additional index to them might with advantage be included in the catalogue.
The work of Mr. Terrick Williams, R.A., entitled "Sun and Mist, Mousehole" (19), is interesting as representing some beautiful changes in appearances due to the dispersion of light through an atmosphere laden with warm vapour.

One outstanding feature of this year's exhibition is the large scale model ( 1 in. to $4 \mathrm{ft}$.) of the Metropolitan Cathedral of Liverpool, made by Mr. John B. Thorp, to the designs of Sir Edwin Lutyens, R.A. Finally, we may direct attention to the remarkable metallic sheen upon the herald's coat in the portrait of Sir Gerald Wollaston, Garter Principal King of Arms (237), by Mr. Harold Knight. The brilliant lustre of polished gold is perfectly imitated, merely by the skilful use of suitable pigments.

\section{Dr. Boys on Gas Calorimetry}

THE nineteenth Guthrie lecture of the Physical Society was delivered on May 4 by Dr. C. V. Boys, one of the Gas Referees, who took as his subject "My Recent Progress in Gas Calorimetry". Lord Rayleigh presided.

After referring to his very close association with Prof. Guthrie, Dr. Boys remarked that "the making of specious scientific surmises unsupported by experiment, however amusing it may be as a pastime or however loudly it may be advertised, does nothing to advance the certain knowledge of the world ; the acid test of experiment is essential. So will you, who in years to come will have the management of this Society in your hands, accept this as a solemn message from the dead. If you would be true to the ideals of Guthrie, you will seek for a Guthrie lecturer from among those who have done things rather than from those who have merely talked."

Proceeding, Dr. Boys stated that he had not been entirely satisfied with the gas calorimeters he had already invented, but now, as the result of work extending over the last nine years, he had designed a calorimeter which gave him complete satisfaction. The essentials of a water-flow calorimeter for measuring the heating value of gas comprise a stream of water to be heated by the combustion of a supply of gas, and means for indicating or recording the resulting rise of temperature of the water stream. As the volume of a given mass of gas depends on its temperature and pressure, it is clear that means must be provided either to correct such volume to standard conditions of temperature and pressure, or alternatively to ensure that water shall flow through the calorimeter at a rate proportional to the uncorrected density of the gas, that is, inversely proportional to the volume at the time of a standard volume of gas.

In his previous recording calorimeter, Dr. Boys utilised the first of these alternatives ; in the present instrument (Fig. 1) the latter alternative is adopted. The appropriate hyperbolic relation is realised practically by a device which ensures that the depth of water in the vessel $A$ is proportional to the density of the gas, and that water is picked up from this vessel and delivered to the calorimeter $F$ in this same proportion. The device comprises (1) the closed burette tube, $D$, containing air or other gas, carried on the radial arm, $C$, and immersed at its lower open end in a vessel containing mercury, (2) four rotating scoops carried on arms for collecting distilled water from the lower vessel $B$ and delivering it to the upper vessel, $A$; these pick up rather more than is required for the calorimeter water; (3) a pair of rotating scoops and delivery vessels, of which one is shown at $E$, for collecting the appropriate volume of water from $A$ and delivering same to the calorimeter proper, $F$. The excess of water escapes from a siphon carried by the arm $C$, thus maintaining the required level. The motive power for driving the mechanism is derived via a 'Meccano' chain from the small electric motor shown at $H$. The water flow system requires the addition of only about 1 gallon of water per annum to replace that lost by evaporation.

The gas-pump, $G$, for supplying gas to the calorimeter, incorporates a number of novel features. Hitherto, the calorific value of gas supplied for towns' use has been measured with reference to a volume of gas saturated with water vapour, at atmospheric temperature. Within recent years, there has been an increasing tendency on the part of gas companies to supply dried gas, that is, gas from which a very considerable proportion of the water vapour ordinarily present has been removed. In order that the calorific value of such, or any other, gas shall be measured with reference to its actual water vapour content, whether saturated or unsaturated, the gas pump, $G$, uses mercury as confining liquid. Briefly, the pump comprises an inner cylinder having six longitudinal compartments accurately reamed out, and rotating within an outer casing. Appropriate inlet and outlet ports are provided for each compartment. The same 